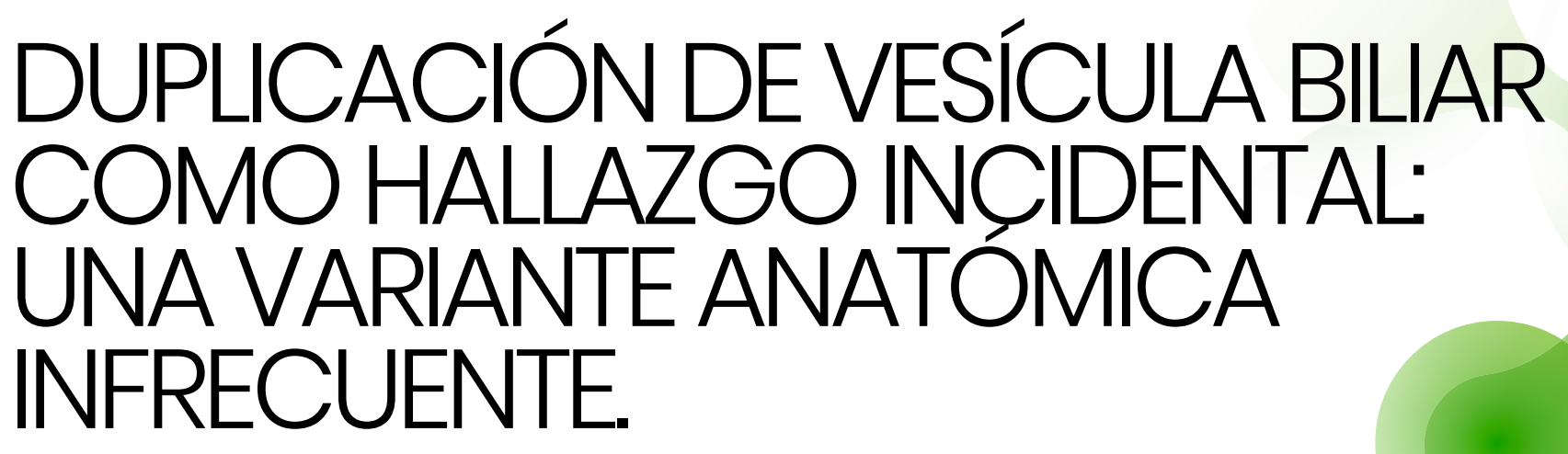

\title{
GALLBLADDER DUPLICATION AS AN INCIDENTAL FINDING: A RARE ANATOMIC VARIANT.
}

\section{Garrido Márquez I, Olmedo Sánchez E, García Pérez PV}

Hospital Universitario Clínico San Cecilio. Granada.

Resumen

La duplicidad de la vesícula biliar es una malformación congénita poco frecuente que puede presentarse de tres formas diferentes en función de la morfología de la propia vesícula y de la vía biliar. La sintomatología que suele provocar es superponible a los casos de vesícula biliar única, siendo la mayor parte de los casos asintomáticos. Es importante realizar un correcto diagnóstico mediante pruebas de imagen para que, en el caso de que tenga que intervenirse quirúrgicamente, orientar al cirujano de forma precisa.

Palabras clave: vesícula biliar, malformación, vesícula doble.

\section{CORRESPONDENCIA}

Irene Garrido Márquez

Hospital Universitario Clínico San Cecilio

18016 Granada

igamar26@gmail.com
Abstract

Duplicity of the gallbladder is a rare congenital malformation that can present in three different ways depending on the morphology of the gallbladder itself and the bile duct. The symptoms that it usually causes is superimposable to the cases of a single gallbladder, with most of the cases being asymptomatic. It is important to make a correct diagnosis through imaging tests so that, in the event that you have to undergo surgery, guide the surgeon precisely.

Keywords: gallbladder, malformation, double gallbladder.

\section{Introducción}

La duplicidad de la vesícula biliar es una malformación congénita poco frecuente que tiene diferentes formas de presentación y que se puede asociar con un aumento del riesgo de complicaciones en el caso de que el paciente tenga que ser intervenido quirúrgicamente. 


\section{Caso Clínico}

Paciente de 70 años con antecedentes de hipertensión arterial (HTA) y apnea del sueño (SAHOS) que acude a Urgencias por dolor abdominal difuso acompañado de fiebre de 380 y deposiciones diarreicas. En la exploración física destacaba dolor focalizado en fosa ilíaca derecha; y en la analítica, una PCR de $250 \mathrm{mg} / \mathrm{dL}$ con procalcitonina de $0,9 \mathrm{ng} / \mathrm{mL}$. Ante la sospecha de ileítis infecciosa o apendicitis, se solicitó una prueba de imagen, realizándose ecografía y completando con TC abdominopélvica sin contraste intravenoso.

Los hallazgos fueron múltiples divertículos en marco colónico, con engrosamiento y cambios inflamatorios predominantes en región cecal/colon ascendente proximal, todo ello en relación con diverticulitis grado IA de Hinchey, no complicada. Incidentalmente, y por lo que presentamos este caso, se visualizó una duplicidad de la vesícula biliar, tipo 1 , como variante anatómica (Figuras 1 y 2). Dicho hallazgo no presentaba otras alteraciones que hicieran sospechar complicación.

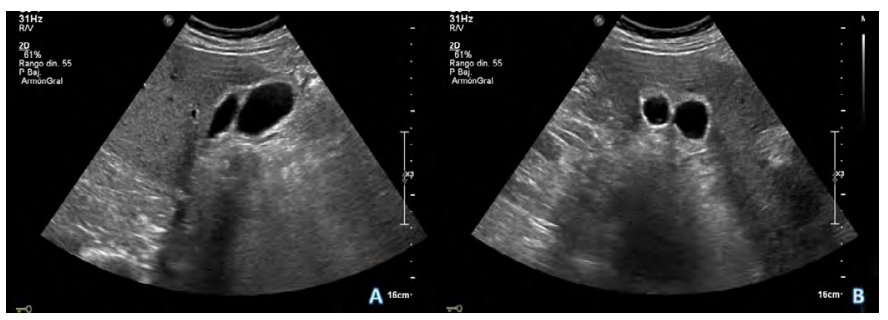

Figura 1

Ecografía abdominal en la que se visualiza una doble vesícula biliar, de paredes no engrosadas y sin signos de complicación.

El paciente fue tratado con amoxicilina-clavulánico y paracetamol durante 7 días, con mejoría de los síntomas.

\section{Discusión}

La duplicación de la vesícula biliar constituye una rara variante de la normalidad que fue descrita por primera vez en 1675 por Blasius et al. ${ }^{1}$ y que tiene lugar en 3800-4000 nacimientos $(1: 4000)^{2}$. Sin embargo, la incidencia exacta de esta anomalía no puede ser evaluada con precisión, ya que los únicos casos que pueden identificarse son aquellos que presentan síntomas o de forma incidental durante laparotomía, estudios de imagen (como nuestro caso, ya que los síntomas no procedían de esta región) o en la autopsia.

Embiológicamente, la vesícula biliar se origina en la cuarta semana del desarrollo a partir de un brote que emerge desde el conducto biliar, correspondiente a un segmento de tejido endodérmico que une el intestino anterior con el primordio hepático. Inicialmente es sólida y alrededor de la séptima semana se canaliza, pasando el pedículo a formar el conducto cístico, y no es hasta la 12a semana cuando se comienza a sintetizar la bilis y a conformar la circulación de la misma hacia el intestino ${ }^{3}$.

La duplicidad vesicular se clasifica en dos grupos en función de su relación con el conducto cístico ${ }^{4}$, constituyendo el grupo uno

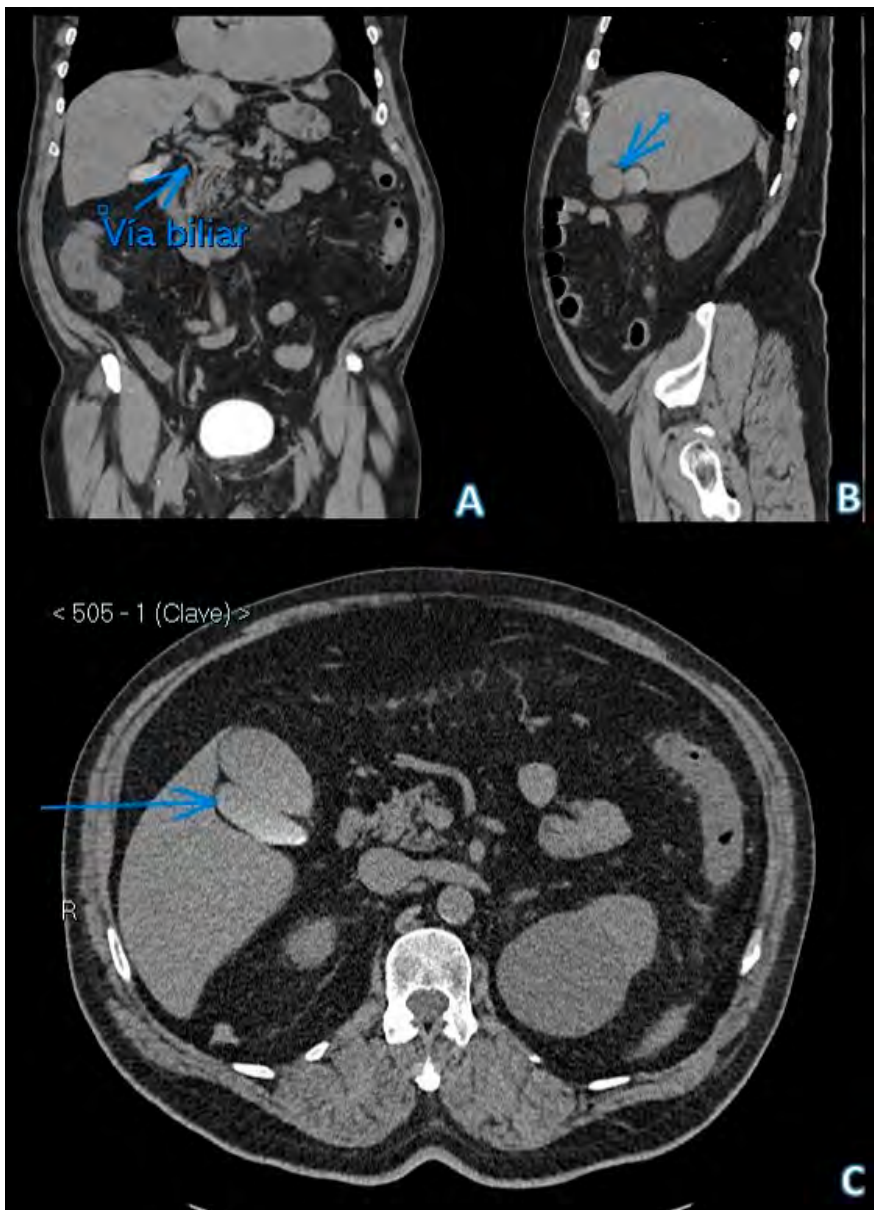

Figura 2

TC abdominopélvica sin contraste intravenoso, cortes coronal (A), sagital (B) y axial (C). Observamos una duplicidad vesicular tipo 1, con vesícula bilobulada así como un único conducto cístico y colédoco.

(vesica fellea divisa) aquellos casos con vesícula bilobulada y un conducto cístico único y el grupo dos (vesica fellea duplex) los que presentan dos vesículas y dos conductos separados. En esta última clasificación, Boyden a su vez la dividió en dos tipos: la forma tipo " $Y$ " consistente en que los dos conductos císticos se fusionan antes de desembocar en el hepático común; y la forma tipo " $\mathrm{H}$ ", en la que cada cístico drena de forma independiente en el conducto hepático común ${ }^{5}$.

En relación a la sintomatología, la clínica es similar a la vesícula biliar única, pudiendo ser asintomática o bien cursar con colelitiasis, colecistitis, colangitis o pancreatitis ${ }^{6}$.

El diagnóstico mediante pruebas de imagen es muy preciso para evaluar el tipo de duplicidad, concretamente la tomografía computarizada y la colangio-resonancia. La ecografía, sin embargo, no puede diferenciar completamente la variante anatómica. En estos casos la clave es determinar la anatomía biliar de forma prequirúrgica, para así evitar lesiones yatrógenas.

El tratamiento de esta malformación es similar al de otras patologías vesiculares, no siendo recomendable la colecistectomía profiláctica en ausencia de sintomatología debido a las posibles complicaciones ${ }^{7}$. No obstante, la colecistectomía laparoscópica es 
el método más recomendado para el manejo de esta anomalía, con resección total de las vesículas presentes, siempre que se disponga de un estudio de imagen previo para orientar al cirujano ${ }^{8}$.

\section{Bibliografía}

1. Boyden E. The accessory gallbladder-an embryological and comparative study of aberrant biliary vesicles occurring in man and domestic mammals. Am J Ant 1926; 38:177-231.

2. Pillay Y. Gallbladder duplication. Int J Surg Case Rep 2015; 11:18-20.

3. Sadler TW. Langman's Medical Embryology. 12th ed. Philadelphia: Wolters Kluwer Health/Lippincott Williams \& Wilkins 2012; 217-20.

4. Kumar M, Adhikari D, Kumar V, Dharap S. Bilobed gallbladder: a rare congenital anomaly. BMJ Case Rep 2018; doi: 10.1136/bcr-2017-222783.
5. Seneca II B, Textier F. Anatomic variability and congenital anomalies of gallbladder: ultrasonographic study of 1823 patients. Morphologie 2000; 84:35-9.

6. Apolo Romero EX, Gálvez Salazar PF, Estrada Chandi JA, González Andrade F, Molina Proaño GA, Mesías Andrade FC, et al. Gallbladder duplication and cholecystitis. J Surg Case Rep 2018; 7:1-3.

7. Goel A, Srivastava KN, Rana AK. Double gallbladder-a laparoscopic management. Surg Laparosc Endosc Percutan Tech 2003; 13:348-9.

8. Aragón Quintana C, García Trujillo U, Duarte Martínez AA, Lirio De Luna Martínez L. Colecistectomía laparoscópica en una duplicación vesicular. Reporte de caso. Rev Mex Cir Endoscop. 2017;18(3-4):125-8. 